\title{
Persepsi Murid Terhadap Layanan Tenaga Administrasi Sekolah Di Sekolah Menengah Kejuruan (SMK) Teknik Negeri Se-Kota Padang
}

\author{
Nadya Mahwadah Tiffani 1, Jasrial2, Nurhizrah Gistituati 3, Yulianto Santoso 4 \\ 1,2,3,4 Administrasi Pendidikan, Universitas Negeri Padang
}

Author ${ }^{1}$, e-mail: nadyamahwadahtiffani@gmail.com

*Author ${ }^{2}$, e-mail: Jasrial36@gamil.com

*Author ${ }^{3}$, e-mail: gistituatinurhizrah@gmai.com

*Author ${ }^{4}$, e-mail: yuliantosantoso@fip.unp.ac.id

\begin{abstract}
This study is to get a sketch of Student Perceptions of School Administrative Personnel Services. This assessment is descriptive quantitative in nature. The population in this study were 870 students of State Technical Vocational High Schools in Padang City. Sampling in this study is proportional random sampling obtained by 84 students. The assessment instrument carried out was in the form of a questionnaire on a linkert scale. This questionnaire has been tested to see its validity and reliability. The results of this study prove that the students' perceptions of the service of school administrative personnel in technical vocational high schools (SMK) in the city of Padang: 1) observed from the timeliness of the assessment by category enough to get an average score of $3.06,2$ ) the aspect of hospitality with a sufficient category by getting an average score of $3.13,3$ ) observed from the aspect of responsibility with a sufficient category by getting an average score of $3.03,4$ ) observed from the aspect of the procurement of supporting facilities with a sufficient category to get an average score - Average $3.33,5)$ observed from the aspects that get service with enough category get an average score of 3.13, and 6) observed from the aspect of comfort who get service with enough category get an average score of 3.30. This examination was denied that the Students' Perceptions of School Administration Personnel Services in the State Technical Vocational School (SMK) Padanf City with a sufficient category got an average score of 3.16. Suggestions that can be given are that efforts are needed to improve Student Perceptions of School Administration Personnel Services to be even better.
\end{abstract}

\begin{abstract}
Abstrak
Pengkajian ini dimaksudkan untuk mendapatkan sketsa tentang Persepsi Murid Atas Layanan Tenaga Administrasi Sekolah. Pengkajian ini sifatnyaDeskriptif Kuantitatif. Populasi pada pengkajian ini adalah siswa-siswi XII di Sekolah Menengah Kejuruan Teknik Negeri Se-Kota Padang berjumlah 870 siswa . Penarikan sampel dalam pengkajian ini yaitu Propotional Random Sampling yang diperoleh sebanyak 84 siswa. Instrumen pengkajian yang dilakukan berupa bentuk angket dalam skala linkert. Angket ini sudah di uji coba untuk melihat validitas dan reabilitasnya. Perolehan dari pengkajian ini membuktikan bahwa Persepsi siswa terhadap layanan pegawai administrasi sekolah pada sekolah menengah kejuruan(SMK) teknik negeri sekota Padang: 1) diamati dari ketepatan waktu pengkajiandeengan bernilai cukup mendapatkan jumlah nilai 3,06, 2) diamati dari aspek keramahan dengan bernilai cukup dengan mendapatkan sjumlah nilai $3,13,3$ ) diamati dari aspek tanggung jawab dengan bernilai cukup dengan mendapatkan jumlah nilai $3,03,4$ ) diamati dari aspek penilaian sarana pendukung dengan bernilai cukup mendapatkan jumlah nilai $3,33,5$ ) diamati dari aspek kemudahan mendapatkan layanan dengan bernilai cukup mendapatkan jumlah nilai 3,13, dan 6) diamati dari aspek kenyamanan yang mendapatkan layanan dengan bernjilai cukup mendapatkan jumlah nilai 3,30. Pengakjian ini disangkal bahwa Persepsi Atas Layanan Tenaga Administrasi Sekolah di Sekolah Menengah Kejuruan (SMK) Teknik Negeri Kota Padanf dengan bernilai cukup mendapatkan jumlah nilai 3,16. Saran yang dapat diberikan adalah perlu upaya untuk meningkatkan Persepsi Murid Atas Layanan Tenaga Administrasi Sekolah menjadi lebih baik lagi.
\end{abstract}

Kata Kunci:Persepsi, Layanan Tenaga Administrasi Sekolah 
Nadya Mahwadah Tiffani 1, Jasrial2, Nurhizrah Gistituati 3, Yulianto Santoso 4 Persepsi Murid Terhadap Layanan Tenaga Administrasi Sekolah Di Sekolah Menengah Kejuruan (SMK) Teknik

Negeri Se-Kota Padang

How to Cite: Author 1, and Author 2. Year. Title Manuscript. Journal Educational Administration and Leadership, Vol (N): pp. XX-XX, DOI:10.24036/XXXXXXXXXX-X-XX

This is an open access article distributed under the Creative Commons 4.0 Attribution License, which permits unrestricted use, distribution, and reproduction in any medium, provided the original work is properly cited. (C2020 by author.

\section{Pendahuluan}

Menurut UU Nomor 20 Tahun 2003 tentang SISDIKNAS pendidikan yaitu suatu usaha yang mewujudkan keadaan belajar dan proses pembelajaran agar siswa aktif dalam mengembangkan potensi yang dimilikinya.

Sekolah yaitu satuan pembelajaran yang ikut bertanggung jawab mewujudkan tujuan pendidikan dengan menyelenggarakan proses pendidikan dan pembelajaran untuk menumbuhkan suatu kemampuan siswa. Dalam melaksanakan tanggungjawab tersebut, sekolah baik yang diselenggarakan yang dikelola secara efektif dan efesien. Bagian komponen penting di suatu lembaga pendididikan, disekolah yaitu pegawai administrasi.

Kedudukan pegawai administrasi yang penting dalam membantu kelnacaran tata administrasi sekolah, kelancaran tata administrasi sekolah memerlukan keahlian dan kepandaian yang cukup dalam aspek administrasi. Undang-Undang Nomor 20 Tahun 2003 menjelaskan tenaga kependidikan yang bekerja dalam melaksanakan administrasi kepegawaian, murid, keuangan, persuratan dan kearsipan. Pentingnya pelayanan tenaga administrasi yaitu sebagai petugas untuk mendukung jalannya suatu pendidikan di lembaga pembelajaran.

Hal ini dapat terlihat dari beberapa fenomena sebagai berikut:

1. Pegawai yang kurang ramah dalam melayani siswa. Hal tersebut dapat dilihat dari setiap siswa selesai berurusan dengan tenaga administrasi sekolah banyak siswa yang mendongkol dan siswa merasa kecewa terhadap pelayanan tenaga administrasi sekolah.

2. Pegawai yang kurang cekatan dalam bekerja sehingga pelayanan dalam bekerja menjadi lambat. Hal tersebut dapat dilihat dari banyak nya siswa yang menunggu di depan ruangan Tata Usaha untuk mengurus berkas-berkas yang dibutuhkan oleh siswa.

3. Pegawai yang memberikan informasi kepada siswa kurang jelas. Hal tersebut dapat dilihat dari siswa yang datang ke meja piket untuk bertanya mengenai informasi yang telah dijelaskan di mading maupun dijelaskan secara langsung.

4. Pegawai administrasi sekolah belum dapat memberikan pelayanan prima yang maksimal. Hal tersebut dapat dilihat dari respon pegawai yang kurang memuaskan terhadap siswa yang membuat siswa merasa tidak puas dengan pelayanan yang di berikan sekolah dalam hal teknis yang dimiliki oleh tenaga administrasi sekolah.

Situasi yang mengundang pandangan buruk murid yaitu terdapat kekecewaan anatara harapan dengan kenyataan murid yang dibagikan sekolah. Masalah tersebut harus diatasi sehingga siswa semakin puas akan layanan nan dialokasikan pegawai administrasi sekolah.

\section{Metode Penelitian}

Jenis pengkajian yang dipakai dalam penegkajian ini menggunakan metode kuantitatif dan pengkajian deskriptif. Arikunto (2010:234) berpendapat bahwa pengkajian deksriptif merupakan pengkajian nan digunakan dalam menyatukan suatu fenomena nan ada, fenomenanya adalah kondisi dalam melakukan pengkajian.

\section{Hasil dan Pembahasan}

\section{Hasil}

a. Persepsi Murid Terhadap Layanan Tenaga Administrasi Sekolah Di Sekolah Menengah Kejuruan (SMK Teknik Negeri Se-Kota Padang Diamati Ke Aspek Ketepatan Waktu Pelayanan

Aspek dalam persepsi siswa ini dilihat dari penunjuk ini adalah a) Ketepatan jadwal layanan, b) Ketepatan jadwal layanan. Secara keseluruhanPersepsi Siswa Terhadap Layanan Tenaga Administrasi Sekolah Di Sekolah Menengah Kejuruan (SMK) Teknik Negeri Se-Kota Padang nan ditinjau dari ketepatan waktu pelayanan mendapatkan skor rata-rata 3,06. Skor ini berada pada kategori Cukup. Artinya ketepatan waktu pelayanan di Sekolah Menengah Kejuruan (SMK) Teknik Negeri Se-Kota Padang bisa dikatakan sudah Cukup baik. 
Skor tertinggi menyinggung Persepsi Murid Terhadap Layanan Tenaga Administrasi Sekolah dilihat dari aspek ketepatan waktu pelayanan yaitu tenaga administrasi sekolah mementingkan kepentingan pribadi dari pada kepentingan siswa dengan skor 3,51 (Cukup). Sedangkan yang mendapatkan skor terendah yaitu tenaga administrasi sekolah menyelesaikan kebutuhan siswa dengan waktu yang telah ditentukan dengan skor 2,57 (Kurang).

b. Persepsi Siswa Terhadap Layanan Pegawai Administrasi Sekolah Di Sekolah Menengah Kejuruan (SMK) Teknik NegeriSe-Kota Padang Diamati Dari Keramahan

Aspek yang terdapat di persepsi siswa ini dilihat dari sub indikator yaitu a) Keramahan, b) Kesopanan, c) Kepeduliaan dan d) Kesabaran.Secara keseluruhanPersepsi Siswa Terhadap Layanan Pegawai Administrasi Sekolah Di Sekolah Menengah Kejuruan (SMK) Teknik Negeri Se-Kota Padang nan diamati dari aspek keramahan mendapatkan skor rata-rata 3,13. Skor ini berada pada kategori Cukup. Artinya keramahan di Sekolah Menengah Kejuruan (SMK) Teknik Negeri Se-Kota Padang bisa dikatakan sudah Cukup baik.

Skor tertinggi menyinggung Persepsi Murid Terhadap Layanan Pegawai Administrasi Sekolah dilihat ke aspek keramahan yaitu tenaga administrasi sekolah bersikap sabar jika siswa komplain terhadap layanan yang diberikan dengan skor 3,42 (Cukup). Sedangkan nan mendapatkan skor terendah yaitu tenaga administrasi sekolah menunjukkan sikap sopan terhadap siswa dengan skor 2,76 (Cukup).

c. Persepsi Siswa Terhadap Layanan Pegawai Administrasi Sekolah Di Sekolah Menengah Kejuruan (SMK) Teknik Negeri Se-Kota Padang Diamati Dari Aspek Tanggung Jawab

Aspek pada persepsi siswa ini dilihat dari penunjuk ini adalah a) Kepastian tanggungjawab pelaksanaan pelayanan, b) Dapat bekerjasama dan c) Tingkat kedisiplinan . Secara keseluruhan Persepsi Siswa Terhadap Layanan Pegawai Administrasi Sekolah Di Sekolah Menengah Kejuruan(SMK) Teknik Negeri Se-Kota Padang yang ditinjau ke aspek tanggung jawab mendapatkan skor rata-rata 3,03. Skor ini berada pada kategori Cukup. Artinya tanggung jawab di Sekolah Menengah Kejuruan (SMK) Teknik Negeri Se-Kota Padang bisa dikatakan sudah Cukup baik.

Skor tertinggi menyinggung Persepsi Siswa Terhadap Layanan Tenaga Administrasi Sekolah dilihat dari aspek tanggung jawab yaitu Tenaga administrasi sekolah dalam mengatasi masalah secara bersama-sama 3,45 (Cukup). Sedangkan nan mendapatkan skor terendah yaitu Tenaga administrasi sekolah melaksanakan tugas dengan penuh disiplin 2,50 (Kurang).

d. Persepsi Siswa Terhadap Layanan Pegawai Administrasi Sekolah Di Sekolah Menengah Kejuruan (SMK) Teknik Negeri Se-Kota Padang Diamati Dari Aspek Ketersediaan Sarana Pendukung

Aspek dalam persepsi siswa ini dilihat dari sub indikator yaitu Sarana untuk mendukung pelayanan. Secara keseluruhan Persepsi Siswa Terhadap Layanan Pegawai Administrasi Sekolah Di Sekolah Menengah Kejuruan (SMK) Teknik Negeri Se-Kota Padang nan ditinjau ke aspek ketersediaan sarana pendukung mendapatkan skor rata-rata 3,33. Skor ini berada pada kategori Cukup. Artinya ketersediaan sarana pendukung di Sekolah Menengah Kejuruan (SMK) Teknik Negeri Se-Kota Padang bisa dikatakan sudah Cukup baik.

Skor tertinggi menyinggung Persepsi Siswa Terhadap Layanan Pegawai Administrasi Sekolah dilihat ke aspek ketersediaan sarana pendukung yaitu Tersedianya kursi dan meja nan cukup dalam melayani siswa 3,82 (Baik). Sedangkan yang mendapatkan skor terendah yaitu Ruangan tenaga administrasi sekolah memiliki fasilitas yang memadai 3,01 (Cukup).

e. Persepsi Siswa Terhadap Layanan Pegawai Administrasi Sekolah Di Sekolah Menengah Kejuruan (SMK) Teknik Negeri Se-Kota Padang Diamati Dari Aspek Kemudahan Mendapatkan Layanan

Aspek dalam persepsi siswa ini dilihat dari indeks ini adalah a) Kemudahan jadwal layanan , b) Kelancaran layanan saat dijumpai dan mengontak, dan c) Kelancaran saat memberikan kriteria layanan. Secara keseluruhanPersepsi Siswa Terhadap Layanan Pegawai Administrasi Sekolah Di Sekolah Menengah Kejuruan (SMK) Teknik Negeri Se-Kota Padang ditinjau ke aspek kemudahan mendapatkan layanan skor rata-rata 3,13. Skor ini berada pada kategori Cukup. Artinya kemudahan mendapatkan layanan di Sekolah Menengah Kejuruan (SMK) Teknik Negeri Se-Kota Padang bisa dikatakan sudah Cukup baik.

Skor tertinggi menyinggung Persepsi Siswa Terhadap Layanan Pegawai Administrasi Sekolah dilihat ke aspek kemudahan mendapatkan layanan yaitu Tenaga administrasi sekolah berada di dalam ruangan 3,73 (Baik). Sedangkan yang mendapatkan skor terendah yaitu Tenaga administrasi sekolah memberikan penjelasan nan mudah dimengerti oleh siswa 2,48 (Kurang).

f. Persepsi Siswa Terhadap Layanan Pegawai Administrasi Sekolah Di Sekolah Menengah Kejuruan (SMK) Teknik Negeri Se-Kota Padang Diamati Dari Aspek Kenyamanan Memperoleh Layanan

Aspek dalam persepsi siswa ini dilihat dari indeks ini adalah a) tranparasi wilayah layanan, dan b) kesiapan alat layanan .Secara keseluruhanPersepsi Siswa Terhadap Layanan Pegawai Administrasi Sekolah Di Sekolah Menengah Kejuruan (SMK) Teknik Negeri Se-Kota Padang ditinjau ke aspek kenyamanan memperoleh layanan dengan skor rata-rata 3,30. Skor ini berada pada kategori Cukup. Artinya kenyamanan 
Nadya Mahwadah Tiffani 1, Jasrial2, Nurhizrah Gistituati 3, Yulianto Santoso 4 Persepsi Murid Terhadap Layanan Tenaga Administrasi Sekolah Di Sekolah Menengah Kejuruan (SMK) Teknik

Negeri Se-Kota Padang

memperoleh layanan di Sekolah Menengah Kejuruan (SMK) Teknik Negeri Se-Kota Padang bisa dikatakan sudah Cukup baik.

Skor tertinggi menyinggung Persepsi Siswa Terhadap Layanan Pegawai Administrasi Sekolah dilihat ke aspek kenyamanan memperoleh layanan yaitu Ruangan tenaga administrasi sekolah tertata sesuai dengan bagian/bidangnya 3,70 (Baik). Sedangkan nan mendapatkan skor terendah yaitu Tenaga administrasi sekolah menggunakan fasilitas nan mendukung dalam memberikan pelayanan terhadap siswa 2,79 (Cukup).

\section{Pembahasan}

\section{a. Persepsi Siswa Terhadap Layanan Tenaga Administrasi Sekolah Dari Aspek Ketepatan Waktu Pelayanan}

Salah satu indikator dari persepsi siswa terhadap layanan administrasi sekolah adalah Ketepatan Waktu Pelayanan. Ketepatan waktu pelayanan adalah pelaksanaan pelayanan menyelesaikan pada waktu nan sudah ditetapkan. Hasil penelitian menunjukkan aspek ketepatan waktu pelayanan memberikan gambaran ratarata3,06 nan sudah terdapat pada kategori cukup, sehingga perlu usaha untuk meningkatkan ketepatan waktu pelayanan pada administrasi sekolah untuk menjadi lebih baik. Hasil penelitian menunjukkan skor tertinggi ada pada item mementingkan kepentingan pribadi dari pada kepentingan siswa dengan skor 3,51. Skor ratarata terendah adalah menyelesaikan kebutuhan siswa sesuai dengan waktu nan telah ditentukan dengan skor2,57.

Kemungkinan penyebab rendahnya nilai Persepsi Siswa Terhadap Layanan Tenaga Administrasi Sekolah dilihat dari aspek ketepatan waktu pelayanan berada pada kategori kurang. Hal ini perlu ditingkatkan kembali oleh tenaga administrasi sekolah dilihat dari aspek ketepatan waktu pelayanan menjadi sangat baik. Situasi yg dikerjakan yaitu memaksimalkan proses pelayanan tenaga administrasi sekolah agar siswa lebih puas terhadap layanan yg dibagikan tenaga administrasi sekolah serta berjalan sesuai yg diharapkan oleh tenaga administrasi sekolah maupun oleh siswa.

b. Persepsi Siswa Terhadap Layanan Tenaga Administrasi Sekolah Dilihat Dari Aspek Keramahan

Salah satu indikator dari persepsi siswa terhadap layanan administrasi sekolah adalah Keramahan. Keramahan adalah sikap kebaikan hati dan keakraban.Hasil penelitian menunjukkan aspek keramahan memberikan gambaran rata-rata 3,13 yang sudah terdapat pada kategori cukup, sehingga perlu usaha untuk meningkatkan keramahan tenaga administrasi sekolah dalam melayani siswa untuk menjadi lebih baik. Hasil penelitian menunjukkan skor tertinggi ada pada item tenaga administrasi sekolah bersikap sabar jika siswa komplain terhadap pelayanan yang diberikan dengan skor 3,42.Skor rata-rata terendah adalah tenaga administrasi sekolah menunjukkan sikap sopan terhadap siswa dengan skor 2,76.

Kemungkinan penyebab rendahnya rata-rata skor Persepsi Siswa Terhadap Layanan Tenaga Adminstrasi Sekolah dilihat ke aspek keramahan berada pada kategori cukup. Hal ini perlu ditingkatkan kembali oleh tenaga administrasi sekolah dilihat ke aspek keramahan menjadi sangat baik. Nan dapat dilakukan yaitu dapat memberikan sikap keramahan dan kesopanan nan lebih baik dalam melayani siswa agar siswa lebih puas dan senang terhadap layanan yang diberikan tenaga administrasi sekolah .

c. Persepsi Siswa Terhadap Layanan Tenaga Administrasi Sekolah Dilihat Dari Aspek Tanggung Jawab

Salah satu indikator dari persepsi siswa terhadap layanan administrasi sekolah adalah Tanggung Jawab. Tanggung jawab adalah pemahaman orang terhadap tingkah laku atau aksi baik yg berniat. Hasil penelitian menunjukkan aspek tanggung jawab memberikan gambaran rata-rata 3,03 yang sudah berada terdapat pada kategoi cukup, sehingga perlu usaha untuk meningkatkan tanggung jawab terhadap layanan tenaga administrasi sekolah dalam melayani siswa sehingga lebih maksimal. Hasil penelitian menunjukkan skor tertinggi ada pada item tenaga administrasi sekolahdalam mengatasi masalah secara bersama-sama dengan skor 3,45.Skor rata-rata terendah adalah tenaga administrasi sekolah melaksanakan tugas dengan penuh disiplin dengan skor 2,50.

Kemungkinan penyebab rendahnya rata-rata skor Persepsi Murid Terhadap Layanan Pegawai Administrasi Sekolah ditinjau dari aspek tanggung jawab berada pada kategori cukup. Hal ini perlu ditingkatkan kembali oleh tenaga administrasi sekolah dilihat dari aspek tanggung jawab menjadi sangat baik. Hal nan dapat dilakukan adalah dengan cara mendisplinkan waktu dalam bekerja sehingga pekerjaan terselesaikan dengan tepat waktu dalam melayani siswa agar siswa lebih puas terhadap layanan nan dibagikan tenaga administrasi sekolah.

d. Persepsi Siswa Terhadap Layanan Tenaga Administrasi Sekolah Dilihat Dari Aspek Ketersediaan Sarana Pendukung

Salah satu indikator dari persepsi siswa terhadap layanan administrasi sekolah adalah Ketersediaan Sarana Pendukung. Hasil penelitian menunjukkan aspek ketersediaan sarana pendukung memberikan gambaran rata-rata 3,33 yang sudah terdapat pada kategori cukup, sehingga perlu usaha untuk meningkatkan ketersediaan sarana pendukung terhadap layanan tenaga administrasi sekolah dalam melayani siswa sehingga layanan yang diberikan menjadi lebih baik dan maksimal. Hasil penelitian menunjukkan skor tertinggi ada 
pada item tersedianya kursi dan meja yang cukup dalam melayani siswa dengan skor 3,82.Skor rata-rata terendah adalah ruangan tenaga administrasi sekolah memiliki fasilitas nan memadai dengan skor 3,01.

Kemungkinan penyebab rendahnya jumlah nilai Persepsi Siswa Terhadap Layanan Tenaga Administrasi Sekolah dilihat dari aspek ketersediaan sarana pendukung berada pada kategori cukup. Hal ini perlu ditingkatkan kembali oleh tenaga administrasi sekolah dilihat dari aspek ketersediaan sarana pendukung menjadi sangat baik. Hal yang dapat melancarkan yaitu menyediakan sarpras yg lebih mendukung pelayanan tenaga administrasi disekolah agar terciptanya kenyamanan dalam pelayanan nan dibagikan tenaga administrasi sekolah kepada siswa.

e. Persepsi Siswa Terhadap Layanan Tenaga Administrasi Sekolah Dilihat Dari Aspek Kemudahan Mendapatkan Layanan

Salah satu indikator dari persepsi siswa terhadap layanan administrasi sekolah adalah Kemudahan Mendapatkan Layanan. Hasil penelitian menunjukkan aspek kemudahan mendapatkan layanan memberikan gambaran rata-rata 3,13 yang sudah terdapat pada kategori cukup, sehingga perlu usaha untuk meningkatkan kemudahan mendapatkan layanan terhadap layanan tenaga administrasi sekolah dalam melayani siswa sehingga layanan yang diberikan menjadi sangat baik. Hasil penelitian menunjukkan skor tertinggi ada pada item tenaga administrasi sekolah berada di dalam ruangan dengan skor 3,73.Skor rata-rata terendah adalah tenaga administrasi sekolah memberikan penjelasan yang mudah dimengerti oleh siswa dengan skor 2,48.

Kemungkinan penyebab rendahnya jumlah nilai Persepsi Siswa Terhadap Layanan Tenaga Administrasi Sekolah dilihat ke aspek kemudahan mendapatkan layanan berada pada kategori kurang. Hal ini perlu ditingkatkan kembali oleh tenaga administrasi sekolah dilihat dari aspek kemudahan mendapatkan layanan menjadi sangat baik.

f. Persepsi Siswa Terhadap Layanan Tenaga Administrasi Sekolah Dilihat Dari Aspek Kenyamanan Memperoleh Layanan

Salah satu indikator dari persepsi siswa terhadap layanan administrasi sekolah adalah Kenyamanan Memperoleh Layanan. Hasil penelitian menunjukkan aspek kenyamanan memperoleh layanan memberikan gambaran rata-rata 3,30 yang sudah terdapat pada kategori cukup, sehingga perlu usaha untuk meningkatkan kenyamanan memperoleh layanan terhadap layanan tenaga administrasi sekolah dalam melayani siswa sehingga layanan nan diberikan menjadi sangat baik. Hasil penelitian menunjukkan skor tertinggi ada pada item ruangan tenaga administrasi sekolah tertata sesuai dengan bidangnya dengan skor 3,70.Skor rata-rata terendah adalah tenaga administrasi sekolah menggunakan fasilitas yang mendukung dalam memberikan pelayanan terhadap siswa dengan skor 2,79.

Kemungkinan penyebab rendahnya jumlah nilai Persepsi Siswa berdasarkan Layanan Tenaga Administrasi Sekolah dilihat dari aspek kenyamanan memperoleh layanan berada pada kategori cukup. Hal ini perlu ditingkatkan kembali oleh tenaga administrasi sekolah dilihat dari aspek kenyamanan memperoleh layanan menjadi sangat baik. Hal nan dilakukan yaitu memberikan fasilitas mendukung serta kenyaman dalam melayani siswa, sehingga pelayanan yang diberikan tenaga administrasi sekolah bisa lebih maksimal agar siswa merasa lebih puas terhadap layanan yang diberikan sekolah.

g. Rekapitulasi Skor Rata-Rata Persepsi Murid Terhadap Layanan Pegawai Administrasi Sekolah

Secara keseluruhan hasil pengelolaan bukti mengenai Persepsi Siswa Terhadap Layanan Tenaga Administrasi Sekolah yaitu:

\begin{tabular}{|l|l|c|c|}
\hline No & \multicolumn{1}{|c|}{ Indikator } & Skor Rata-rata & Keterangan \\
\hline 1 & Ketepatan waktu pelayanan & 3,06 & Cukup \\
\hline 2 & Keramahan & 3,13 & Cukup \\
\hline 3 & Tanggung jawab & 3,03 & Cukup \\
\hline 4 & Ketersediaan sarana pendukung & 3,33 & Cukup \\
\hline 5 & $\begin{array}{l}\text { Kemudahan mendapatkan } \\
\text { layanan }\end{array}$ & 3,13 & Cukup \\
\hline 6 & $\begin{array}{l}\text { Kenyamanan memperoleh } \\
\text { layanan }\end{array}$ & 3,30 & Cukup \\
\hline
\end{tabular}


Nadya Mahwadah Tiffani 1, Jasrial2, Nurhizrah Gistituati 3, Yulianto Santoso 4 Persepsi Murid Terhadap Layanan Tenaga Administrasi Sekolah Di Sekolah Menengah Kejuruan (SMK) Teknik

Negeri Se-Kota Padang

\section{Kesimpulan}

Berlandaskan jumlah pengkajian dan bahasan pandai mengambil sinopsis: a) Persepsi Siswa Terhadap Layanan Tenaga Administrasi Sekolah dilihat dari aspek ketepatan waktu pelayanan mampu atas bagian cukup perolehan jumlah nilai 3,06, b) Persepsi Ssiwa Terhadap Layanan Pegawai Administrasi Sekolah mampu atas bagian keramahan berkategori cukup perolehan jumlah nilai 3,13, c) Persepsi Siswa Terhadap Layanan Tenaga Administrasi Sekolah dilihat dari aspek ketersediaan sarana pendukung mampu atas bagian cukup dengan perolehan jumlah nilai 3,03, d) Persepsi Murid Terhadap Layanan Pegawai Administrasi Sekolah ditinjau dari aspek tanggung jawab atas penilaian cukup perolehan nilai 3,33, e) Persepsi Siswa Terhadap Layanan Tenaga Administrasi Sekolah dilihat dari aspek kemudahan mendapatkan layanan atas penilaian cukup dengan jumlah nilai3,13, f) Persepsi Siswa Terhadap Layanan Tenaga Administrasi Sekolah dilihat dari aspek kenyamanan memperoleh layanan atas penilaian cukup perolehan nilai 3,30.

\section{Daftar Rujukan}

Arikunto, S. (2010). Prosedur Penelitian Suatu Pendekatan Praktik. Rineka Cipta.

UU Nomor 20 Tahun 2003 tentang SISDIKNAS Pendidikan 